\title{
Nanocellulose: Preparation, Characterization and Applications
}

\author{
A. Krishna Shailaja*, B. Pranaya Ragini, \\ RBVRR Women's College of Pharmacy, Affiliated to Osmania University, Barkatpura, Hyderabad (Osmania University)-500027
}

*Corresponding Author A. Krishna Shailaja, RBVRR Women's College of Pharmacy, Affiliated to Osmania University, Barkatpura, Hyderabad (Osmania University)-500027.

Received date: November 05, 2021; Accepted date: December 11, 2021; Published date: January 03, 2022

Citation: A. Krishna Shailaja,(2022) Nanocellulose: Preparation, Characterization and Applications. Pharmaceutics and Pharmacology Research. 5(1); DOI: 10.31579/2693-7247/039

Copyright: (c) 2022, A. Krishna Shailaja, This is an open access article distributed under the Creative Commons Attribution License, which permits unrestricted use, distribution, and reproduction in any medium, provided the original work is properly cited.

\begin{abstract}
:
The growth of nanocellulose has attracted outstanding interest in the last few decades due to its unique and potentially useful features. Novel nanocelluloses improve the strongly expanding field of sustainable materials and nanocomposites.CNCs and CNFs are two kind of nanocelluloses (NCs), and they own various superior properties, such as large specific surface area, high tensile strength and stiffness, low density, and low thermal expansion coefficient.Their application includesnanocellulose in transdermal drug delivery, Hydrogels, Aerogel Systems, Nanocellulose in Tablet Formulations and Nanocellulose in Microparticulate Drug Delivery (1). Different methods of nanocellulose like pretreatment method, mechanical process and chemical hydrolysis used for the synthesis of nanocellulose. Characterization of cellulose includes scanning electron microscopy, $\mathrm{x}$-ray diffraction (XRD) analysis of samples and thermogravimetric analysis.
\end{abstract}

Key words: nanocrystals; electro spun cellulose nanofibers; Bacterial cellulose; micro fluidization

\section{Introduction}

Cellulose is the main component of the plant cell wall and can be removed from a variety of sources, such as wood, fibers, grasses, seed fibers, marine animals, algae, fungi, invertebrates, and bacteria. Apart from cellulose, the plant cell wall also carries hemicellulose, lignin, and small amount of extractives. Even though wood species are the chief origin of cellulose, nonfood plants are accepting increasing interest due to their low-cost availability and bottom lignin content. Consequently, their fiber purification procedure are uncomplicated and less energy absorbing. For these causes, different agriculturalconsequences are under in-depth study for the manufacturing of various product ranges ${ }^{(2)}$.Derivatizing cellulose obstruct with the orderly crystal-forming hydrogen bonding, so that even hydrophobic derivatives may grow the apparent solubility in water. Methylcellulose, Cellulose acetate, Ethyl cellulose, Carboxymethylcellulose and native cellulose have been used in various industrial applications and these include; barriers films, thickener and emulsifier, lubricant, glue and binder, artificial tears and saliva, optical and biomedical devices, pharmaceutical raw materials, flame retardants, resins and filters, blends and composites. Because of their low cost, toughness, natural feel, transparency, softness, comfort and other favorable aesthetic properties (3). Nanocellulose has obtained growingprofit for a wide range of requesting relevant to the areas of materials science and biomedical engineering due to its renewable nature, anisotropic shape, excellent mechanical properties, better biocompatibility, tailorable surface chemistry, and interesting optical properties. A new scope of nanocellulose application is still under investigation in fields such as photonics, films and foams, surface modifications, nanocomposites ${ }^{(4)}$, flexible optoelectronics, and medical devices like scaffolds for tissue regeneration. The most beneficial property of nanocellulose research is the green nature of the particles, their fascinating physical and chemical properties, and the diversity of applications that can be derived from this material ${ }^{(5)}$.

\section{Cellulose:}

Cellulose was first find by Payen. Since then, the physical and chemical properties of cellulose have been considered intensively. It is a wellordered fibrillar ranging that is primarily answered for the mechanical strength of plants ${ }^{(6)}$. It is considered as one of the most plentiful organic complex obtained from plant biomass. Around 1010 and $1011 \mathrm{t}$ of cellulose biopolymer are produced each year but only about $6 \times 109 \mathrm{t}$ are used by various industries such as paper, textile, material and chemical industries, etc. In spit cellulose is a crystalline molecule its crystallinity is faulty; a notablepart of the cellulose building is less commanded and can be mentioned to as amorphous. Thus, the cellulose chain is a two-phase modelholding both crystalline (ordered) and amorphous (less ordered) regions ${ }^{(7)}$. The grade of crystallinity of domestic cellulose usually ranges from $40 \%$ to $70 \%$ depending on the origin of cellulose and the separationmethod. The cellulose is present in the form of the microfibrils, which are bound together by lignin and hemicellulose. These microfibrils are made up of tiny cells having width of $10-50 \mu \mathrm{m}$, depending on the source $^{(8)}$.

\section{Nanocellulose:}


In recent years, nanocellulose synthesis and application has achieved remarkable growth as polymer reinforcement in order to create highperformance biomaterials. Cellulose molecules with at least one dimension in nanoscale $(1-100 \mathrm{~nm})$ are mentioned to as nanocellulose. The main reason for increasing interest in nanosized material is due to the fact that highly uniform material with enhanced mechanical properties can be achieved by reducing the size of the cellulose fiber [8]. It is considered a sustainable material due to its biodegradable nature. The characteristic properties of nanocellulose like crystallinities, surface area, and mechanical properties vary with the extraction methods and processing techniques ${ }^{(9)}$. For example, CNC synthesis by sulfuric acid requires the selective hydrolysis of amorphous cellulose regions and results in highly crystalline particles with source-dependent dimensions. Negative charged sulfate groups are attached onto the surface of CNC particles, which restricts the aggregation of particles in aqueous suspensions due to electrostatic repulsion. Depending on the technique and synthesis conditions of nanocellulose, which determines its dimensions, composition and properties, it can be divided into three main categories:

1. cellulose nanocrystals (CNCs), also known as cellulose whiskers

2. cellulose nanofibrils (CNFs), also known as nano fibrillated cellulose (NFC), micro fibrillated cellulose (MFC) or cellulose nanofibers

3. bacterial cellulose (BC) and electro spun cellulose nanofibers (ECNFs)

Type of Nanocellulose

\section{Cellulose nanocrystals:}

Cellulose nanocrystals (CNCs) are frequently produced using acid hydrolysis of cellulosic materials dispersed in water. In general, concentrated sulfuric acid is used, which dissolves the amorphous regions of cellulose and the crystalline regions are left alone. Although this procedure produces a rod-like rigid $\mathrm{CNC}$ with almost $90 \%$ purity, the sulfate groups remain attached at the surface of the fibers as impurities (10). The length and diameter of CNCs commonly vary from a length of $200-500 \mathrm{~nm}$ to a diameter of $3-35 \mathrm{~nm}$.

\section{Cellulose nanofibrils:}

CNFs are long entangled fibrils $(\mu \mathrm{m})$ with a diameter in nanometer range. CNFs are produced by high-pressure grinding of cellulosic pulp suspension and strongly entangled networks of nanofibrils are formed ${ }^{(11)}$. Unlike CNCs, which have near-perfect crystallinity (c.90\%), CNFs contain both amorphous as well as crystalline cellulose domains within the single fibers. Typically, CNFs have a diameter of 5-50 nm and a length of a few micrometers. CNF extraction from cellulosic fibers can be obtained by three types of processes: (1) mechanical treatments (e.g., homogenization, grinding, and milling); (2) chemical treatments (e.g., TEMPO oxidation); and (3) a combination of chemical and mechanical treatments.

\section{Bacterial cellulose:}

Bacterial cellulose (BC) is also known as microbial cellulose. It is usuallyproduced from bacteria, (e.g., Acetobacterxylinum) as an unrelated molecule and does not need additional handling to remove contaminants like lignin, pectin, and hemicellulose.Furthermore, in disparity to $\mathrm{CNC}$ and $\mathrm{CNF}$ biosynthesis, $\mathrm{BC}$ biosynthesis requires the addition of molecules from tiny units $(\AA)$ to small units $(\mathrm{nm})^{(12)}$. In the biosynthesis of $\mathrm{BC}$, the glucose chains are provided inside the bacterial body and discharge out through minor pores present on the cell wall. Ribbon-shaped BC nanofibers are established when glucose is fused with the cell wall. This ribbon-like web-shaped structure build a $20-100 \mathrm{~nm}$ long unique nanofiber system.

\section{Preparation of Cellulose Nanocrystals:}

CNCsowngiant crystallinity with diameter less than $100 \mathrm{~nm}$ and length less than $500 \mathrm{~nm}$, which are established through intermolecular interaction of cellulose macromolecules in a hydrogen bond way. CNCs are generally obtained through acid hydrolysis or enzymatic hydrolysis of cellulose pulp. Acid hydrolysis processes need to go through very harsh reaction conditions which usually require concentrated acid, while the enzymatic hydrolysis process requires really long time. There are mainly determined by the inherent stable structure of the materials that have been explained in a related review. During the hydrolysis activity, the amorphous regions of cellulose are more easily invested by acid compared to the crystalline regions, leading to first degradation of amorphous regions, while the crystalline regions are retained. Finally, whisker-like CNCs are obtained. In retrospect, the first successful mixture of CNCs was in 1947 all the time hydrolyzing cellulose with hydrochloric acid and sulfuric acid by Nickerson and Habrle. In 1951, Ranby prepared the stable CNCs colloidal suspensions ${ }^{\circ}$ through sulfuric acid hydrolysis of wood fiber. In 1953, Mukherjee and Woods proved that the needle particles obtained by sulfuric acid hydrolysis occult nanometer size by X-ray technology and electron microscope and found that their crystal structure was same as that of raw cellulose material. Subsequently, Marchessaults et al. found that the CNCs colloid suspension had birefringence. After that, some new methods to prepare CNCs seemsslowly, such as enzymatic hydrolysis, oxidative degradation, ionic liquid, solid acid hydrolysis, organic acid hydrolysis, and subcritical hydrolysis.

\section{Mineral Acid Hydrolysis}

The mineral acid hydrolysis is the most ordinary method for the preparation of CNCs. Many cellulose sources have been used for the preparation of CNCs by mineral acid hydrolysis, such as tomato peel, oil palm biomass, rice husk, and waste cotton cloth. The classic mechanism is that the hydrogen ions from acid can easily pervade the loose amorphous regions of cellulose to break the 1,4- $\beta$-glycoside bonds, resulting in the hydrolysis of amorphous regions, while the crystalline region of cellulose could be keep in the process which is ascribed to the inherent compact structure that averted the permeation of the acid. Hence, the relatively complete crystalline structure of CNCs can be obtained by the hydrolysis of mineral acid.

Fig:1 Schematic diagram of CNCs prepared by acid hydrolysis: (a) idealized cellulose microfibril showing one of the suggested configurations of the crystalline and amorphous regions and (b) CNCs after acid hydrolysis dissolved the disordered regions. 


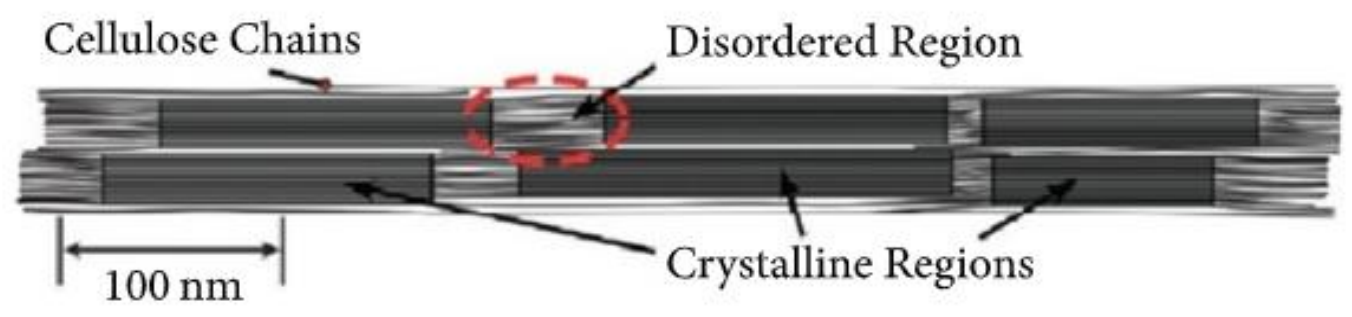

(a)

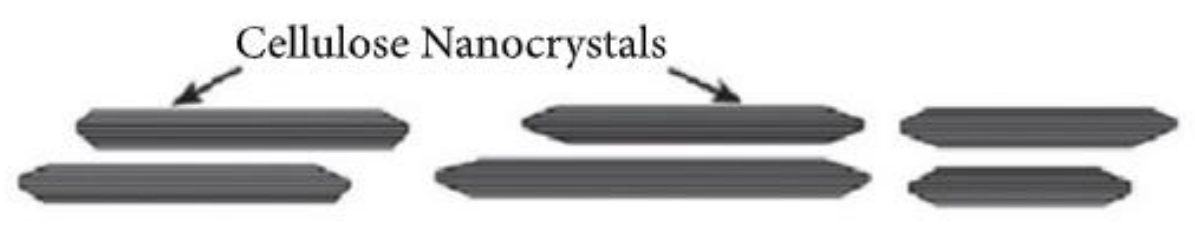

(b)

The usually used mineral acids are sulfuric acid, hydrochloric acid, phosphoric acid, hydrobromic acid, and their mixed acids. Sulfuric acid is the most usually used as it produces a negative surface charge on the particles which guide to more stable suspension. In general, the hydrolysis process needs the sulfuric acid congregation to be $60-65 \%$, reaction temperature to be $40-50^{\circ} \mathrm{C}$, and reaction time to be $30-60 \mathrm{~min}$. However, the yield of CNCs is very low (less than $30 \mathrm{wt} . \%$ ) due to the intemperate degradation. Fan and $\mathrm{Li}$ optimized the sulfuric acid hydrolysis circumstances with cotton pulp as raw material, and the yield of CNCs reached to $63.8 \%$. Chen et al. found that the yield of CNCs could be remarkably improved by decreasing the concentration of sulfuric acid and prolonging reaction time. For example, the yield of CNCs could extend to $75.6 \%$ when $58 \mathrm{wt} . \%$ sulfuric acid was used at $56^{\circ} \mathrm{C}$ for $210 \mathrm{~min}$. CNCs from sulfuric acid hydrolysis have poor thermal stability due to the sulfate group which is a remarkable barrier for thermal process in composites. The thermal stability of CNCs can be improved between neutralization with $\mathrm{NaOH}$. The morphology of CNCs can be also changed by controlling the reaction conditions. The spherical CNCs with average dimension of $35 \mathrm{~nm}$ could be obtained by using $63.5 \% \mathrm{H}_{2} \mathrm{SO}_{4}$ to hydrolyse microcrystal cellulose under the ultrasonic ministration combined with mechanical stirring for $3 \mathrm{~h}$. Azrina et al. also reported a commom condition for the preparation of spherical CNCs. This reaction was carried out with $64 \%$ (w/v) $\mathrm{H}_{2} \mathrm{SO}_{4}$ solution at $45^{\circ} \mathrm{C}$ for $2 \mathrm{~h}$ in an ultrasound bath. In this reaction, the spherical CNCs with an average diameter of 30-40 nm were synthesised from oil palm empty fruit bunch pulp.

Hydrochloric acid also was frequently used for the preparation of CNCs. The classic acid concentration, reaction temperature, and reaction time are $2.5 \mathrm{~N}-6.0 \mathrm{~N}$, reflux temperature, and $2-4 \mathrm{~h}$, respectively. Due to the absences of charge on the surface of CNCs, the CNCs prepared by hydrochloric acid are easily flocculation in water. But the thermal stability of $\mathrm{CNCs}$ by $\mathrm{HCl}$ is more than that by $\mathrm{H}_{2} \mathrm{SO}_{4}$. Yu et al. used hydrochloric acid to treat raw cellulose materials under hydrothermal situations. The crystallinity of the resultant CNCs was $88.6 \%$ with greater yield of $93.7 \%$. The maximum degradation temperature was $363.9^{\circ} \mathrm{C}$ which was resolved by TGA analysis. Cheng et al. described an inorganic chloride/hydrochloric acid system for extracting CNCs from microcrystalline cellulose (MCC) under hydrothermal conditions. Four inorganic chlorides including $\mathrm{FeCl}_{3} 6 \mathrm{H}_{2} \mathrm{O}, \mathrm{CuCl}_{2} 2 \mathrm{H}_{2} \mathrm{O}, \mathrm{AlCl}_{3}$, and $\mathrm{MnCl}_{2} 4 \mathrm{H}_{2} \mathrm{O}$ were look over in this work. The research allow that the hydrolysis process was support significantly by inorganic chlorides especially ferric chloride via accelerating degradation of the amorphous region of cellulose. Phosphoric acid, which belongs to middle strong acid $(\mathrm{pKa}=2.12)$, could be used for the preparation of CNCs with high thermal stability and stable suspension. Lu et al. reported a mechanochemical proceed towards to manufacture bamboo cellulose nanocrystals (BCNCs). In this action, the bamboo cellulose pulp was chemically treated by phosphoric acid. Finally, short rod-like BCNCs with the length of $100-200 \mathrm{~nm}$ and the width of $15-30 \mathrm{~nm}$ was obtained. The crystalline building transformed from cellulose I to cellulose II, and the crystallinity index reduced from 66.44 to $59.62 \%$, while the thermal stability became lower.

Hydrobromic acid ( $\mathrm{HBr}$ ) hydrolysis circumstances assisted with ultrasonication to prepare CNCs were investigated by Sadeghifar et al. When the hydrolysis process was carried out at $2.5 \mathrm{M} \mathrm{HBr}$ under $100^{\circ} \mathrm{C}$ with sonication for $3 \mathrm{~h}$, CNCs could be obtained at a yield of $60 \%$. Moreover, Sucaldito and Camacho used $\mathrm{HBr}$ to hydrolyze fresh water green algae to attain the highly crystalline CNCs (crystallinity index of $94.0 \%$ ). The resultant CNCs have a mean diameter of $20.0( \pm 4.4) \mathrm{nm}$, and the rotting temperature reached $381.6^{\circ} \mathrm{C}$. 


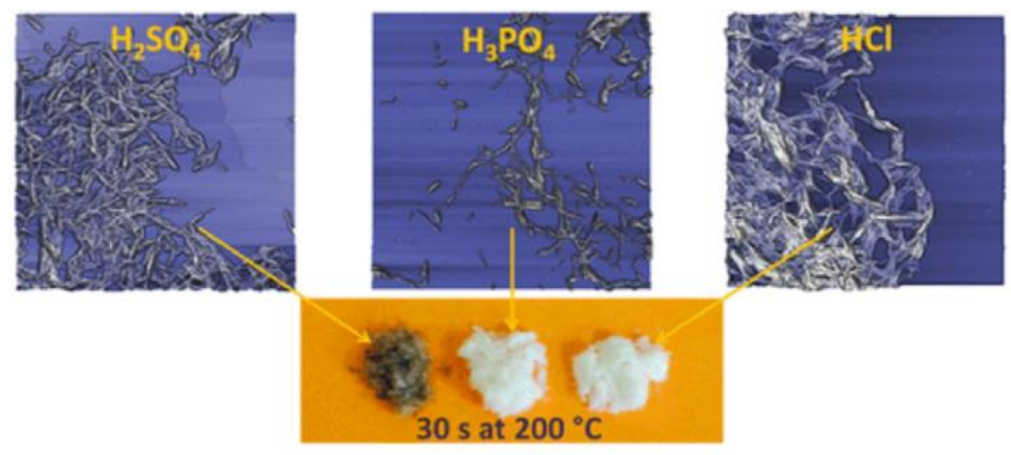

Fig:2 Schematic diagram thermal stability contrast of CNCs from sulfuric acid hydrolysis, hydrochloric caid hydrolysis or phosphoric acid hydrolysis.

Spherical CNCs could be also prepared by using a mixed acid system facilitated with ultrasonication from MCC. The mixed acid system is a mixture of sulfuric acid (98\%, w/w), hydrochloride (37\%, w/w), and $\mathrm{H}_{2} \mathrm{O}$ at a ratio of 3:1:6 (v/v) which was reported by Zhang et al. The action was carried out at $80^{\circ} \mathrm{C}$ by ultrasonicator heating for $8 \mathrm{~h}$. The diameters of produced cellulose nanoparticles are in the range of $60-570 \mathrm{~nm}$. The hydrolysis condition provided by Wang et al. was, the ratio of sulfuric acid (98\%, w/w), hydrochloride (37\%, w/w), and $\mathrm{H}_{2} \mathrm{O}$ was still 3: 1: 6 $(\mathrm{v} / \mathrm{v})$, while the ultrasonic treatment was at $50 \mathrm{~Hz}$ for $10 \mathrm{~h}$. The resultant spherical CNCs suspension with the dimension of $10-180 \mathrm{~nm}$ showed liquid crystalline quality when the concentration was above $3.9 \%$. A mixed acid system of hydrochloric acid and nitric acid $\left(\mathrm{HCl} / \mathrm{HNO}_{3}\right)$ could be used to developcarboxylated cellulose nanocrystals (CCNCs) from MCC. When the reaction was support out under the mixed acid $\left(\mathrm{HCl} / \mathrm{HNO}_{3}=7: 3(\mathrm{v} / \mathrm{v})\right)$ concentration being $4 \mathrm{M}$ at $110^{\circ} \mathrm{C}$ for $3 \mathrm{~h}$, the resultant $\mathrm{CCNCs}$ were rod-like morphology and had good suspension stability and excellent thermal stability.

Generally, mineral acid hydrolysis method to produce CNCs is a simple method and has gone to pilot scale (quite a few around the world) and even exhibition plant ( 1 tonne/day at CelluForce, Canada). However, there are still some demerits in this method. First, the corrosion problem of the equipment is serious which leads to the arrogant cost of production. Furthermore, a large amount of waste acid and other pollutants will be produced in the procedure of acid hydrolysis, and it is very difficult to dispose and recover. So, it is very necessary to develop green and lowcost CNCs production technologies.

\section{Solid Acid Hydrolysis}

Tang et al. reported a cation interchange resin hydrolysis method for the preparation of $\mathrm{CNCs}$. By hydrolyzing $\mathrm{MCC}$ with cation trading resin
(NKC-9), an optimum yield (50.04\%) was achieved with a ratio of resin to $\mathrm{MCC}(\mathrm{w} / \mathrm{w})$ being 10 and at $48^{\circ} \mathrm{C}$ for $189 \mathrm{~min}$. The results showed that the diameter of CNCs was about $10-40 \mathrm{~nm}$ and the length was 100 $400 \mathrm{~nm}$. The crystallinity of resin-CNCs was excessive than that of $\mathrm{H}_{2} \mathrm{SO}_{4}$-CNCs. In counting to the recoverable capacity of cation exchange resin, the cation exchange resin-catalysed hydrolysis is a favourable approach for manufacturing of CNCs. Liu and co-workers reported the phosphotungstic acid (HPW) catalysed-hydrolysis procedure with bleached hardwood pulp as raw material. CNCs with the diameter of 15$40 \mathrm{~nm}$ were given, which had high thermal solidity and stable dispersion in watery phase. The reaction was support out with $75 \mathrm{wt} . \%$ phosphotungstic acid at $90^{\circ} \mathrm{C}$ for $30 \mathrm{~h}$; the yield of CNCs was up to $60 \%$. Phosphotungstic acid could be retrieve through extraction with available ethyl ether. Since this method is a solid/liquid/solid three-phase reaction, the reaction efficiency is low and the reaction time is comparatively long compared with the mineral acid hydrolysis method. Further research results showed that the response time was notably shortened under the optimal conditions, and the obtained CNCs had a high crystallinity index (79.6\%) with a $84 \%$ yield. Torlopov et al. also reported a CNCs preparation procedure using phosphotungstic acid/acetic acid method to destruct cotton cellulose. The resulting $\mathrm{CNCs}$ have high-crystalline method and rod-like morphology.Contrast with the typical mineral acid hydrolysis method, solid acid hydrolysis method has mild surrounding and low corrosion to equipment, and the solid acid can be recycled. Moreover, the yield of CNCs is higher. However, the reaction order is low and the reaction time is pretty long. Allocate physical approach (such as microwave and ultrasound assisted) or suitable catalyst could be used to better the reaction efficiency. At present, solid acid hydrolysis method to prepare $\mathrm{CNCs}$ is still in the phase of laboratory research.

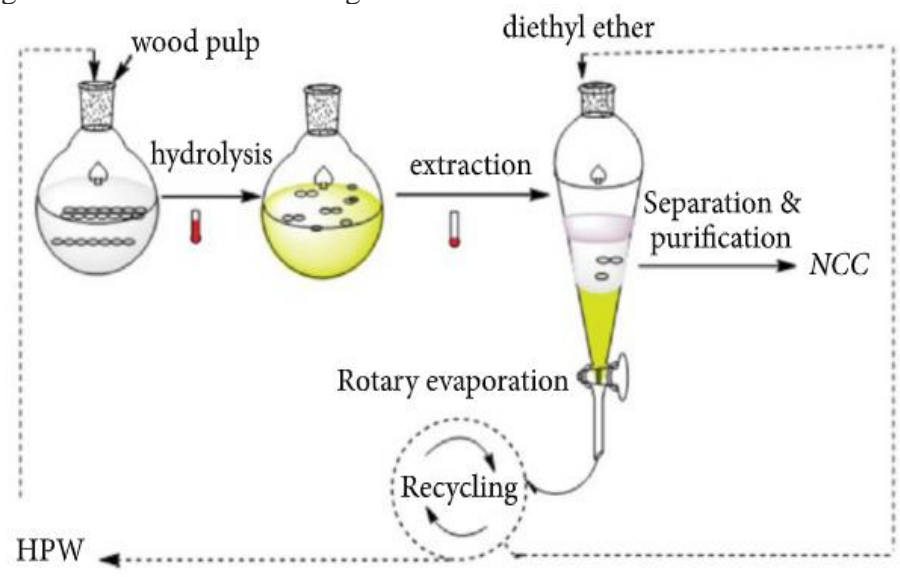

Fig:3 The overall procedure for manufacturing CNCs by using HPG 


\section{Organic Acid Hydrolysis}

Recently, organic acid hydrolysis was introduce to produce NCs due to the fact that the organic acid is mild, recyclable, and environment-friendly and of low corrosiveness. However, in order to improve the efficiency of hydrolysis, higher temperature and prolonged reaction time are necessary because of the weak acidity of organic acid. Li and co-workers reported a two-step master plan to produce CNCs from bleached chemical pulp under mild conditions. In the first stage, formic acid (FA) was used to hydrolyse the amorphous region of cellulose and free CNCs. In the second stage, the cause CNCs were further oxidized by TEMPO in order to grow the surface charge. The results manifested that the crystallinity index of resultant $\mathrm{CNCs}$ could reach $75 \%$ when $0.015 \mathrm{M} \mathrm{FeCl} 3$ was used. Moreover, up to $90 \%$ FA can be retrieve by rotary evaporation, $\mathrm{FeCl}_{3}$ could be recovered in the form of $\mathrm{Fe}(\mathrm{OH})_{3}$ precipitation cause by ammonia treatment, and the generated ammonium salt can be used as fertilizer. Thus, the $\mathrm{FeCl}_{3}$-catalyzed $\mathrm{FA}$ hydrolysis action was more sustainable than the normal sulfuric acid hydrolysis process. Then, dicarboxylic acid was used for CNCs production suggested by Chen et al.
Similarly, CNCs usually were obtained at a low yield due to the low reactive pursuit of dicarboxylic acid. Thus, most of the hydrolysedresult are the insufficiently hydrolysed fibers which can be used for preparing CNFs through following mechanical disintegration. The merits of using dicarboxylic acid for the mixture of NCs are that (1) carboxyl groups are introduced on the surface of CNCs and CNFs, as ester group could have been shape by the reaction of dicarboxylic acids with cellulose ; (2) solid dicarboxylic acid (e.g., oxalate and maleic acid) is of low corrosion to equipment and could be totally recovered by using crystallization technology; (3) the resultant CNCs and CNFs are thermally stable which is beneficial for the manufacture of compound. $\mathrm{Li}$ and co-workers used molten oxalate dihydrate to tend cellulose fibrils which is a free solvent for the preparation of CNCs. In this operation, the hydrolysis and esterification of cellulose could be carried out in one pot. CNCs could be reached in a high yield (80.6 wt.\%). Xu and co-workers successfully prepared the CNCs with a mixed acid collected of hydrochloric acid and oxalate. The optimal problem is that the concentration of oxalate is $0.11 \mathrm{M}$ with $10 \% \mathrm{HCl}$ at $95^{\circ} \mathrm{C}$ for $4 \mathrm{~h}$. Results showed that $\mathrm{CNCs}$ could be acquire with a high yield of $81.5 \%$.

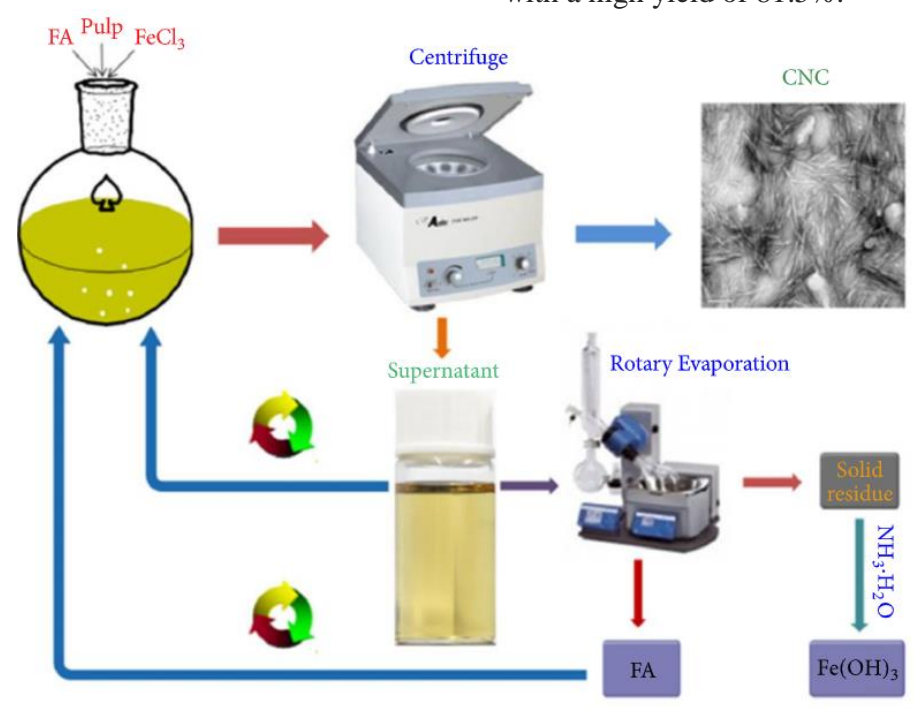

Fig:4 Overall flow process diagram of preparation of CNCs by fecl3

Maleic acid was also used for the preparation of CNCs and the pretreatment of cellulose. Wang and co-workers reported the preparation of $\mathrm{CNCs}$ utilize maleic acid to hydrolysecellulose. CNCs were obtained at a low yield, about $5 \%$. The fibrous cellulosic solid residue could be converted to CNFs through the backing mechanical disintegration. Bian et al. used concentrated maleic acid to hydrolyse unbleached mixed hardwood kraft pulp. The results were that the lignin-contain CNCs and CNFs were successfully prepared. Bian and co-workers also reported a maleic acid catalysed-hydrolysis response for the preparation of CNCs and CNFs. The bleached eucalyptus pulp and unbleached mixed hardwood kraft pulp were used as the raw materials, and classic operating conditions were acid concentrations of $50-70 \mathrm{wt} . \%$ at $100-120^{\circ} \mathrm{C}$ for $1-$ $2 \mathrm{~h}$. The results showed that CNCs with the length of approximately 239$336 \mathrm{~nm}$ were prevail, and CNFs could be reached by the further mechanical fibrillation of fibrous cellulosic solid residue. Yu et al. described an approach for extracting carboxylated CNCs by citric acid/hydrochloric hydrolysis of MCC. In this work, rod-like CNCs with the length of $200-250 \mathrm{~nm}$ and the width of $15-20 \mathrm{~nm}$ were prevail. The $\mathrm{CNCs}$ extracted for $4 \mathrm{~h}$ had the greatest carboxylic group content and high zeta potential value (up to $-46.63 \mathrm{mV}$ ). By applying organic acid hydrolysis, some absorbing functional groups could be introduced to the surface of CNCs through the ester bond between organic acid and CNCs in the hydrolysis process. For example, Boujemaoui et al. used 2- bromopropionic acid, 3-mercaptopropionic acid, 4-pentenoic acid, and 2propynoic acid, respectively, to catalyse the hydrolysis of raw cellulose materials. Some active functional groups such as Br-, HS-, alkenyl, and alkynyl were grafted on the surface of CNCs correspondingly, which could be advantageous to further modify CNCs despite the very long reaction time (10 days).Generally, organic acid hydrolysis is more sustainable and environment-friendly than mineral acid hydrolysis for CNCs production. It is believed that the industrialization of CNCs by using organic acid hydrolysis will be perceive in recent years.

\section{Enzymatic Hydrolysis}

Cellulase is a multicomponent enzyme system. Its active partincludes endoglucanases (EG), cellobiohydrolases $(\mathrm{CBH})$, and $\beta$-glucosidase (GB). The action mechanism of each part on cellulose is shown in Figure 5. EG mostly acts on the amorphous region of cellulose to randomly hydrolyse the $\beta$-1,4-glycosidic bond, so the long chain cellulose molecules are shorten into small molecular cellulose in the interior of cellulose; CBH mainly acts on the end of linear cellulose molecular to demolish the crystalline region of cellulose; GB is used to hydrolyse cellulose into glucose. When $\mathrm{CNCs}$ are prepared by enzymatic hydrolysis, the demolish of the crystalline area of cellulose by $\mathrm{CBH}$ should be avoided as much as possible. Therefore, three part of cellulase should be isolate from each other. EG is used to hydrolyse cellulose 
amorphous regions, and much more crystalline regions are kept in the process. Filson and co-workers successfully prepared CNCs utilize endoglucanase to hydrolyse recycled pulp. They found that when the endoglucanase was increased to $420 \mathrm{EGU}$ per $1 \mathrm{~g}$ pulp and the reaction temperature was at $50^{\circ} \mathrm{C}$ with microwave heating for $60 \mathrm{~min}$, the $\mathrm{CNCs}$ with the diameter of $30-80 \mathrm{~nm}$ and the length of $100 \mathrm{~nm}-1.8 \mu \mathrm{m}$ could be obtained, the yield was up to $38.2 \%$, the average zeta potential was $-31.37 \mathrm{mV}$, and birefringence could be observed for the CNCs dispersion. Chen et al. prepared a ball-shaped nanosized cellulose by the enzymatic hydrolysis of pulp fibers. This research allows that enzymatic hydrolysis of pulp could give spherical CNCs with the diameter of ca. $30 \mathrm{~nm}$, which had
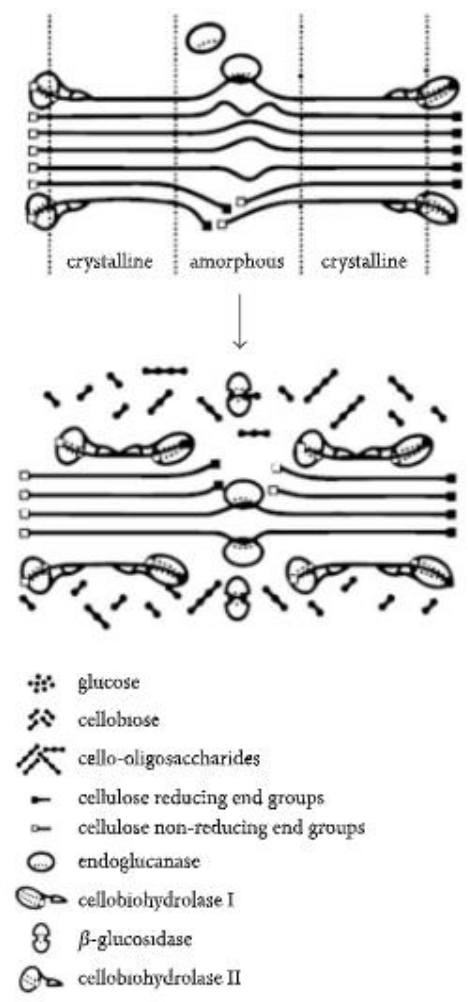

Fig:5 schematic diagram of different cellulase impact of cellulose

good monodispersity and uniformity. When the concentration of composite enzymes was $20 \mathrm{u} / \mathrm{mL}$ (cellulase: xylanase $=9: 1$ ), the yield of $\mathrm{CNCs}$ reached to $13.6 \%$. However, when the single cellulase was used, even if the enzyme concentration extended up to $200 \mathrm{u} / \mathrm{mL}$, only a blended of strip and granular flocculation was obtained. Meyabadi et al. also reported the enzymatic hydrolysis method to manufactured the spherical CNCs with waste cotton as raw material merge with sonication. The particle sizes of gained CNCs were less than $100 \mathrm{~nm}$. Overall, compared with the mineral acid hydrolysis, the enzymatic hydrolysis process for the preparation of CNCs is environment-friendly, while the experimental circumstances are harsh, the yield of CNCs is low, and the reaction time is long. Enzymatic hydrolysis of raw cellulose materials is promising for the industrial manufacturing of CNCs, so further research of efficient enzymatic hydrolysis is peremptory and urgent.

\section{Oxidation Degradation}

The hydroxyl groups on cellulose have high reactivity. They are easily oxidized by strong oxidants to aldehydes, ketones, and carboxyl groups so that their structures are destructed and the degree of polymerization is decreased. Therefore, some scientists have successfully prepared CNCs by use of the oxidation degradation method. Yang et al. adopted two-step oxidation procedure to prepare CNCs: softwood pulp was firstly oxidized by sodium periodate and then further oxidized by sodium chlorite, andultimately two-step centrifugation was implemented to give CNCs (diameter/length, $13 \mathrm{~nm} / 120-200 \mathrm{~nm}$ ) and microfibrils (diameter/length, $120 \mathrm{~nm} / 0.6-1.8 \mu \mathrm{m}$ ). The resultant microfibrils could be further relocated to $\mathrm{CNFs}$ by mechanical agitation. The isolated $\mathrm{CNCs}$ with carboxyl groups on the surface had a high crystallinity (91\%) and high charge density which could form a stable suspension in aqueous phase.

Ammonium persulfate (APS) as well could be used to prepare carboxyl CNCs. Hu et al.'sinvestigatesresults showed that the spherical shape particles with diameters of 20-70 $\mathrm{nm}$ were obtained by this method, and the crystallinity of CNCs was remarkably improved after a series of chemical treatments. The researchoutcome of Mascheroni and co-workers showed that CNCs produced through the APS treatment displayed higher charge densities, crystallinity, lucidity of the solution and transparency of the coating contrast to the $\mathrm{CNCs}$ produced by the $\mathrm{H}_{2} \mathrm{SO}_{4}$ hydrolysis. Leung and co-workers used the APS to oxidize the flax fibers to make the surface-carboxylated CNCs. The CNCs were needle-like with diameter of $3.8 \mathrm{~nm}$ and length of $150 \mathrm{~nm}$, and the particle size distribution was uniform. In this method, the raw materials (such as hemp, flax, straw etc.) could be used directly for the preparation of CNCs without pre-treatment process for the delignification. The reason is that APS has the delignin task in addition to oxidative degradation. Cheng and co-workers prepared the CNCs with $1 \mathrm{~mol} / \mathrm{L}$ APS aqueous mixture to oxidize lyocell fiber at $80^{\circ} \mathrm{C}$ for $16 \mathrm{~h}$. The prepared CNCs were spherical with the diameter of $35 \mathrm{~nm}$ and a prominent deal of carboxyl groups were initiate on the surface of CNCs. The crystal kind of resultant CNCs was cellulose II.

TEMPO was also used as oxidation to prepare carboxyl CNCs. Although, only subfraction of raw cellulose materials was oxidized to $\mathrm{CNCs}$ by using TEMPO; the rest of oxidized cellulose had much larger dimensions. It indicated that TEMPO was not as potent as APS on cellulose oxidation. Moreover, CNCs from TEMPO oxidation are highly carboxylated, which provides the opportunity for functionalization .

Altogether, compared with the mineral acid hydrolysis and enzymatic hydrolysis, the yield of CNCs was higher by the oxidation degradation method. However, in the process of reaction, a large number of oxidants were consumed, and the reaction time was longer. Also, a large amount of water and energy need to be consumed which leads to the fact that the cost of CNCs production was very high.

\section{Ionic Liquid Method}

Ionic liquid is a type of organic salt solution with low melting point (less than $100^{\circ} \mathrm{C}$ ) composed of organic cations and other anions. Contrast to the traditional solvent, ionic liquid has advantages in terms of chemical stability, thermal stability, nonflammability, and low vapor pressure. It is also called "green solvent". In recent years, due to the unique belongings on of ionic liquid, it has been widely used to dissolve and separate 


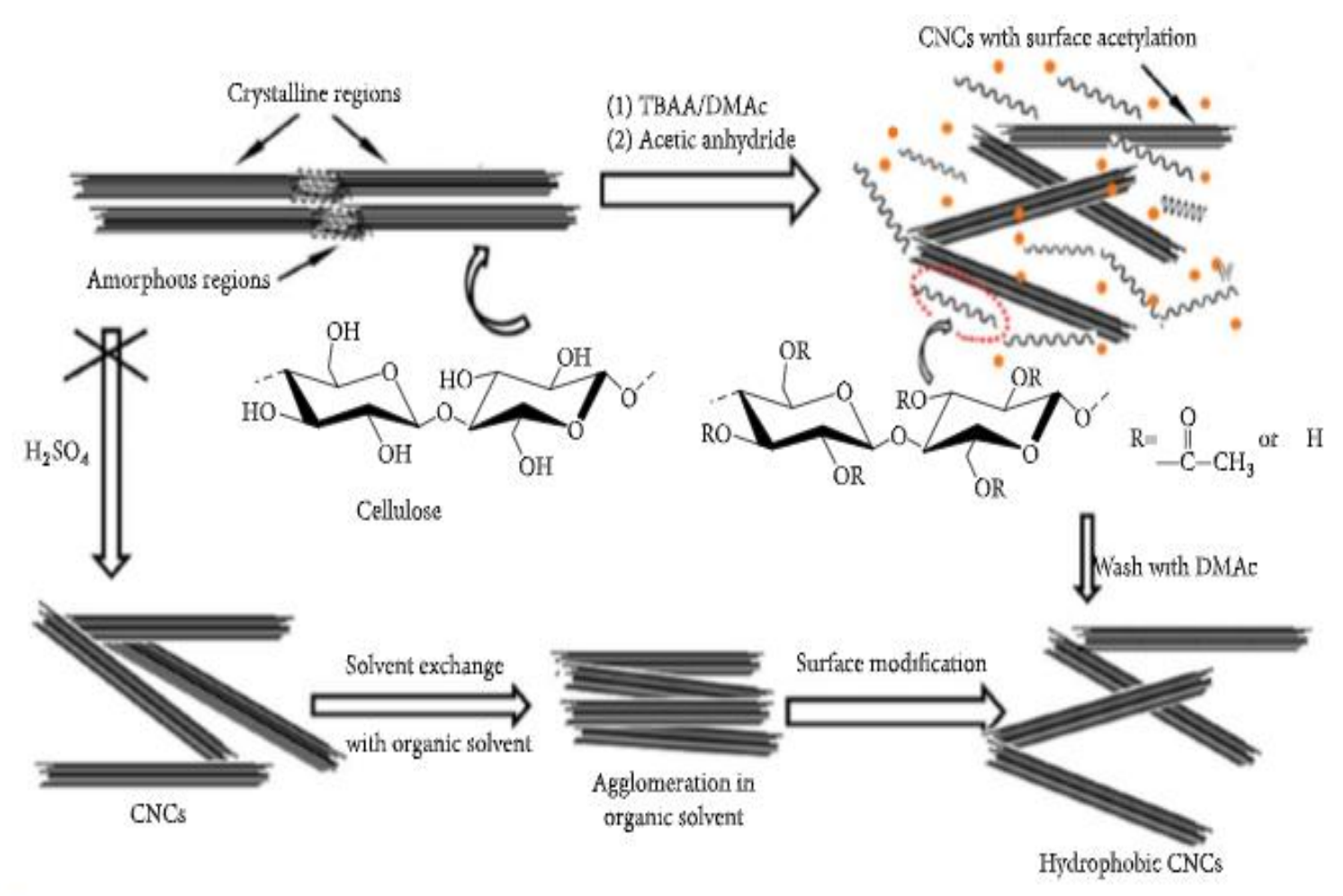

- TBAA/DMAc, released carboxylic acid and the excess of use anhydride

Fig:6 one-pot preparation of hydrophobic CNCs in TBAA with acetic hydride.

Lignocellulose and to prepare CNCs. Man, and co-workers treated MCC with 1-butyl-3-methylimidazolium bisulfate ([BMIM] $\mathrm{HSO}_{4}$ ) to give CNCs with the diameter of 14-22 nm and the length of 50-300 nm. It was found that, compared with the authentic MCC, the CNCs remained cellulose I, while the thermal stability was notablydecreased. Mao and coworkers treated $\mathrm{MCC}$ with [BMIM] $\mathrm{HSO}_{4}$ aqueous solution at $120^{\circ} \mathrm{C}$ for $24 \mathrm{~h}$ to allow the CNCs at $48 \%$ yield.Later, they hydrolysed softwood, hardwood, and MCC by the optimizing two-stage method with $\left[\mathrm{BMIM} \mathrm{HSO}_{4}\right.$ aqueous, and the yield of $\mathrm{CNCs}$ was $57.7 \%, 57 \%$, and $75.6 \%$, respectively, which was close to the theoretical value. Tan et al. used [BMIM] $\mathrm{HSO}_{4}$ as both catalyst and solvent to prepare CNCs from MCC. Highly crystallized CNCs with diameter of $15-20 \mathrm{~nm}$ and length of $70-80 \mathrm{~nm}$ were obtained at $90^{\circ} \mathrm{C}$. Lazko and co-workers reported another system which is that cotton fibers were infiltrated firstly by [BMIM] $\mathrm{Cl}$ at $80^{\circ} \mathrm{C}$, and $1-4 \mathrm{wt} . \%$ sulfuric acid was added subsequently. Then the reaction was kept for $2-16 \mathrm{~h}$, and the CNCs were successfully prepared with the diameter of about $20 \mathrm{~nm}$ and the length of $150-350 \mathrm{~nm}$. The analysis results showed that the CNCs prepared by [BMIM]Cl had less sulfonic class content on the surface than that of [BMIM] $\mathrm{HSO}_{4}$, and their thermal stability was obviously increased. Iskak et al. used $[\mathrm{BMIM}] \mathrm{Cl}$ as ionic liquid to formulateCNCs. In this work, they investigated the effects of the reaction time and temperature on the yield, size, and crystallinity index of CNCs. The results showed that CNCs with the particle size of $9 \mathrm{~nm}$ and the crystallinity index of $73 \%$ were prevail when the reaction time was $30 \mathrm{~min}$. For now, when reaction temperature was $100^{\circ} \mathrm{C}$, CNCs were obtained with a yield of $90 \%$ and crystallinity index of $76 \%$. Abushammala and coworkers personally treated wood with 1-ethyl-3-methyl imidazole acetate ([EMIM][OAc]), and the surface acetylated CNCs were successfully prepared in a $44 \%$ yield. The type of resultant $\mathrm{CNCs}$ was cellulose I, and the crystallinity was $75 \%$. The research showed that [EMIM][OAc] had three main functions in the process: (1) dissolving cellulose in situ when cotton fibers were infiltrated, (2) reducing intermolecular cohesion in wood by acetylation;
(3) catalysing the hydrolysis reaction of cellulose. Miao and co-workers used tetrabutylammonium acetate/dimethylacetamide (TBAA/DMAc) system with acetic anhydride to treat hardwood pulp to gain the hydrophobic CNCs remarkably. The traditional method of preparing hydrophobic CNCs included three steps: firstly, CNCs were prepared by sulfuric acid hydrolysis; secondly, CNCs were dispersed in an organic solvent by solvent exchange; finally, the $\mathrm{CNCs}$ were hydrophobically alter in organic solvent. Compared with classical method, TBAA/DMAc and acetic anhydride structure can be used to prepare hydrophobic CNCs in one pot. The process is simple, and the prepared CNCs with high thermal stability have acetyl group on the surface.

\section{Cellulose nanofibrils synthesis methods:}

Cellulose nanofiber, nanofibrillar cellulose, and cellulose nanofibril are the conditions used for nano fibrillatedcellulose. The mixture of CNFs needs strong mechanical machining. However, according to the properties of raw materials and stage of processing, chemical pretreatments are carried out before mechanical machining. A detail is that appropriate pretreatments of cellulosic fibers can increase the inner surface, alter crystallinity, and break hydrogen bonds of cellulose.

\section{Pretreatment Method:}

Pretreatment of wood cellulose fibers is a procedure to reduce the energy depletion of mechanical nano fibrillationoperation to improve the degree of nano fibrillation. Since energy consumption is the main drawback for the production of nanofibers by mechanical isolation processes, the pretreatment process has become an important step ${ }^{(13)}$. Furthermore, it improves the fibrillation process with increase in production of nanofibers.

\section{Solvent-Assisted Pretreatments}

Traditionally, the cellulose pulp is pre-treated by dilute base. For instance, bleached kraft bagasse pulp was pre-treated with the aqueous solution of 
$5 \% \mathrm{NaOH}$ at $50^{\circ} \mathrm{C}$ for $45 \mathrm{~min}$ so as to get clear of the residual hemicellulose and lignin and then was further ground to obtain the CNFs. Degree of polymerization and cellulose pacify of the resultant CNFs were higher than the ones untreated or hydrolysed with xylanase enzyme. Lee and co-workers used a low-concentration alkaline solution as pretreatment condition $\left(2 \mathrm{wt} . \% \mathrm{NaOH}\right.$ solution below $\left.0^{\circ} \mathrm{C}\right)$ to make CNFs. The resulting CNFs with $90 \mathrm{~nm}$ diameter had relatively elevated thermal stability. The maximum thermal decay temperature was $343^{\circ} \mathrm{C}$, while it was $310^{\circ} \mathrm{C}$ for the $\mathrm{CNF}$ s prepared without the $\mathrm{NaOH}$ pre-treatment. Since urea and ethylenediamine have the capacity to loosen the hydrogen bonds and solubilize cellulose, they could be applied to pre-treat cellulose. Before further mechanical disintegration, a microemulsion (surfactantoil-water systems) as well as urea or ethylenediamine was applied to treat kraft pulps. It was found that urea and ethylenediamine pre-treatment could virtually accelerate the isolation of CNFs.

\section{Organic Acid Hydrolysis Pretreatment}

Recently, some organic acids, for example, formic acid and oxalate, were used to ease the cellulose. Co-workers used highly distilled formic acid to hydrolyse bleached softwood pulp; then the formic esterified MCC passed through homogenizer without clogging to permitCNFs. The resultant CNFs showed high thermal stability (onset decomposition temperature ac. $291^{\circ} \mathrm{C}$ ) and good dispersibility in DMSO, DMAc, and DMF, respectively, due to the introduction of surface formic ester groups. Bian et al. used toluene sulfonic acid (50-80 wt.\%) for the rapid and nearly complete dissolution of wood lignin at $80^{\circ} \mathrm{C}$ for $20 \mathrm{~min}$ (see Figure 10). In this action, the birch wood fiber fractions were hydrolysed to lignocellulosic solid residue (LCSR) that was subsequently fibrillated into lignocellulosic nanofibrils (LCNFs). The dissolved lignin could be precipitated as lignin nanoparticles (LNPs) by diminish the concentration of -TsOH to less than $10 \%$, and the $-\mathrm{TsOH}$ could be retrieve by using commercially proven crystallization technology. The dicarboxylic acid was also used as the pretreatment of lignocellulose to prepare lignin restrain cellulose nanocrystals (LCNCs) and LCNFs by Bian et al. The resultant LCNCs and LCNFs were less carboxylated contrast to those lignin-free CNCs and CNFs. Therefore, they had under charges. Overall, organic acid hydrolysis is amethodicalpre-treatment method, which is recycle and has low corrosion to equipment, and ester groups or carboxyl groups are transplant onto the surface of cellulose in the pre-treatment process.

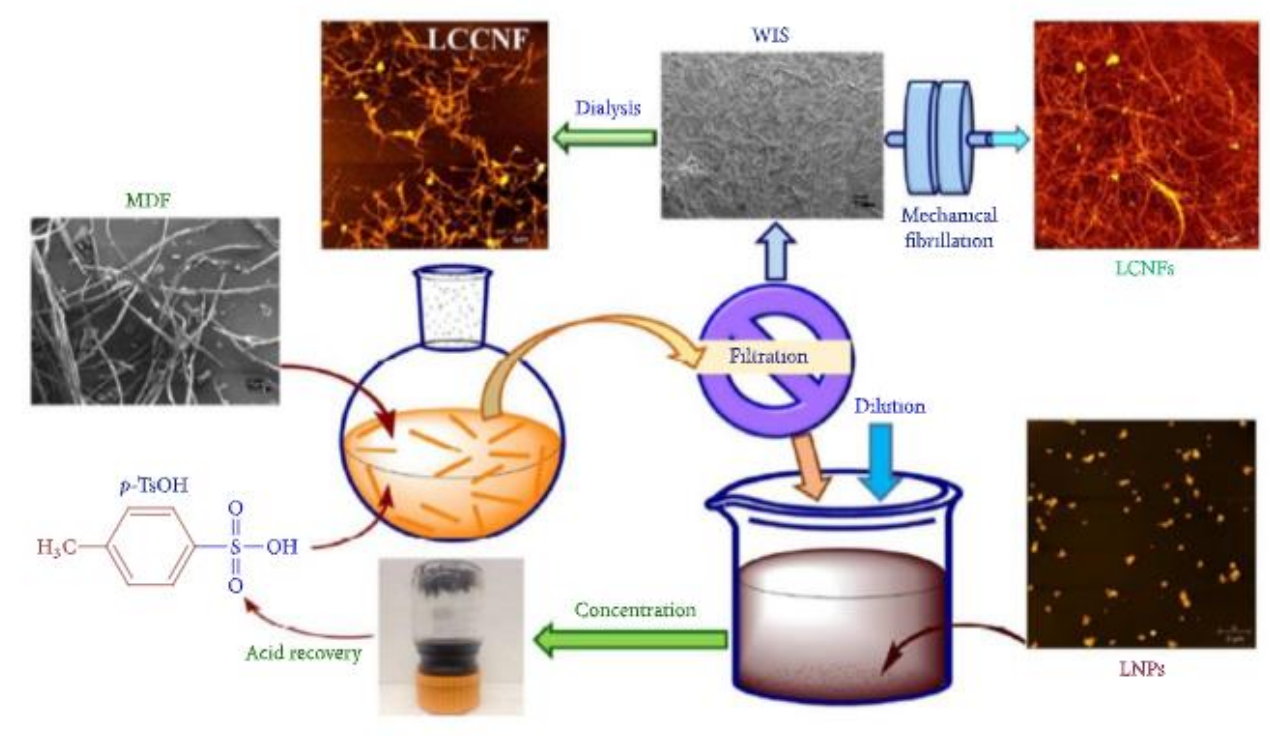

\section{Schematic diagram of preparation of LCNFs LNPs by using p-TsOH pretreatment}

\section{Alkaline-acid:}

Alkaline-acid pretreatment is the most common method used for lignin, hemicellulose, and pectin solubilization before mechanical isolation of NFC. This method included the following steps. 1. Sodium hydroxides $(\mathrm{NaOH})$. Soaking fibers in $12-17.5 \%$ wt solution for about 2 hours. This raises the surface area of cellulosic fibers and eases the hydrolysis. 2. Hydrochloric acid (HCL). Drenched fibers in $1 \mathrm{M}$ solution at $60-80^{\circ} \mathrm{C}$. This solubilizes the hemicelluloses ${ }^{(14)}$. 3. Sodium hydroxides $(\mathrm{NaOH})$. Treating with $2 \mathrm{wt} \%$ solution for 2 hours at $60-80^{\circ} \mathrm{C}$. This disrupts the lignin structure, and breaks the linkages between carbohydrate and lignin. Alkaline pretreatment is an successful method that can enhance cellulose yield from $43 \%$ to $84 \%$. It also helps to removed lignin and hemicelluloses partially from soy hull fibers and wheat straw ${ }^{(15)}$.

\section{Ionic liquids:}

Ionic liquids (ILs) are organic salts owning special possessions such as nonflammability, thermal and chemical stability, and infinitely low vapor pressure ${ }^{(16)}$. It is an increasing interest of researchers to study as solvents of cellulosic materials. Li, Wei treated sugarcane bagasse with 1-butyl-3- methylimidazolium chloride $[(\mathrm{Bmim}) \mathrm{Cl}]$ as ionic liquid and followed the high-pressure homogenization (HPH) technique to prepare NFC. The pulp passed through homogenizer without clogging; these fibers were then precipitated in water solution and regenerated by freeze-drying.

\section{Mechanical Process:}

Cellulosic materials are required to go through mechanical treatment for defibrillation. Pretreatment processing, either by chemicals or enzymes, is done before mechanical fibrillation to ease the process. Chemical treatments help in widening the space between hydroxyl groups, increasing the inner surface, altering crystallinity, and breaking cellulose hydrogen bonds, thus enhancing surface areas, which helps boost the reactivity of the fibers ${ }^{(17)}$. There are many mechanical methods for converting cellulosic fiber to nanocellulose, such as homogenizing,micro fluidization, grinding,cryocrushing, and high-intensity ultrasonication.

\section{Micro fluidization:}

Microfluidizers work near to HPH in the manufacturing of nanocellulose fiber. Microfluidizers use an intensifier pump to enhance pressure, while 
the interaction chamber is used for shear and impact forces against colliding streams to defibrillate the fibers. Lee et al. studied the particular ratio of cellulose fiber and noticed that NFC fiber with higher surface area could be acquired by multiple passes through the microfluidizer ${ }^{(18)}$. The cellulose fibrils revealed a higher amount of hydroxyl $(\mathrm{OH})$ groups as well as agglomeration operation due to more surface area. The number of passes between the homogenizer determine the size of NFC and its surface area.

\section{Ball milling process:}

Ball milling is a mechanical process in which cellulose suspension is placed in a hollow cylindrical container for the production of CNF. This hollow cylindrical container is partially filled with balls made up of ceramic, zirconia, or metal; the container rotates and breaks cellulose cell walls through the high-energy collision between the balls. Zhang, Tsuzuki studied various factors affecting manufacturing of CNF such as ball size, ball-to-cellulose weight ratio, grinding time, moisture content, and carboxylic charge ${ }^{(19)}$. Maintaining homogeneity of the produced CNF is always a major challenge in this method.

\section{Grinding Method}

Ultrafine friction grinding is another ordinary technique for the preparation of CNFs. The commonly used equipment is Super masscolloider grinder. Taniguchi and Okamura used Masuko's colloider grinder for the first time to grind 5-10 wt.\% cellulose materials for 10 times and remarkablyformulated CNFs with diameter of 20-90 nm. Since then, this procedure has attracted wide attention. Gane et al. determined that adding kaolin or calcium carbonate is helpful for accelerating grinding in the grinding operation and will prepare composite of CNFs and a mineral. The working principle is that cellulose materials are sent to the grinding area consisting of a portable disc and a fixed disc, and the process of high-speed grinding and shearing was carried out to give CNFs lastly. Compared to the high-pressure homogenization method, grinding process has the advantages of high efficiency, large capacity, low energy consumption, and being less prone to material clogging. However, because of the strong mechanical force in the grinding procedure, the fiber damage is more serious. As a result, the CNFs property is not well, such as low crystallinity and lesser thermal stability, which leads to the low physical strength of CNFs and the enhancement result of material not as good as CNFs prepared by high pressure homogenization.

\section{Twin-Screw Extrusion Method}

Twin-screw extrusion is another procedure for CNFs production. In the preparation action, cellulose pulp is fibrillated by two corotating, intermeshing screws mounted in a closed barrel. The merits of twin-screw extrusion is that CNFs can be obtained with high solid contents (25$40 \mathrm{wt} . \%$ ), which is very beneficial for transportation and storage. The twin-screw extrusion procedure of the composites from thermoplastic starch and TEMPO-oxidized cellulose fibers was studied by Cobut and co-workers. The CNFs with the diameter of ca. $30 \mathrm{~nm}$ were obtained during extrusion procedure. Hietala and co-workers studied this procedure for the bleached cellulose from softwood flour (particle size of $200-400 \mu \mathrm{m}$ ) as raw materials. The result was that CNFs were not gained; however, fibers with good dispersion in the starch matrix were given. Ho and co-workers studied this technique for the preparation of CNFs from never-dried refined needle-leaf bleached kraft pulp, and the resultant CNFs were obtained at a solid content of $45 \mathrm{wt} . \%$. Overall, twin-screw extrusion technique is promising for the scale production of CNFs.

\section{Cryocrushing Method}

Cryocrushing technique for the preparation of CNFs was studied by Dufresne and co-workers for the first time. The process is that water swollen cellulosic fibers were frozen firstly by liquid nitrogen and subsequently crushed by mortar grinding. Under mechanical impact, the pressure on the cell walls obtained from ice crystals caused cell wall to break and release cell wall fragments. Sain and co-workers studied the fibrillation of agricultural crops using cryocrushing technique. The results showed that the CNFs with the diameter of $50-100 \mathrm{~nm}$ and the crystallinity of $48 \%$ could be derived, and the soybean stock nanofibers could be dispersed in acrylic oligomer emulsion as good as in water.

\section{Blending Method}

Uetani and Yano remarkably prepared CNFs by using the high-speed blender to shear never-dried bleached softwood pulp. The resultant CNFs had a constant diameter of $15-20 \mathrm{~nm}$ when $0.7 \mathrm{wt} . \%$ cellulose pulp suspension was blended at $37,000 \mathrm{rpm}$. Jiang and Hsieh blended the cellulosic fibers suspension at $37,000 \mathrm{rpm}$ and $97^{\circ} \mathrm{C}$ under distinct time conditions (up to $2 \mathrm{~h}$ ) to give the NCs with bimodal size distribution: (i) one was with the diameter of $2.7 \mathrm{~nm}$ and the length in range of 100 $200 \mathrm{~nm}$; (ii) the other was with the diameter of $8.5 \mathrm{~nm}$ and the length with few micrometres . Nakagaito and co-workers improved the blender bottle, and the results showed that the time was halved for fibrillation procedure.

\section{Aqueous Counter Collision}

Aqueous counter collision (ACC) is an another technology for CNFs preparation. Under high coercion, two jets of cellulose suspensions collide against each other, leading to wet pulverization of cellulose and freeing of CNFs. Kose et al. prepared CNFs from the previously homogenized bacterial cellulose aqueous suspension at a concentration of $\leq 0.4$ wt. $\%$ using ACC technique. The procedure was carried out under the ejecting pressure of $200 \mathrm{MPa}$ for 80 passes. The result was that CNFs with the diameter of ca. $30 \mathrm{~nm}$ were make and cellulose $\mathrm{I} \alpha$ changed to cellulose $\mathrm{I} \beta$ after ACC. But the crystallinity was still kept at $>70 \%$. Kondo and workers reported the preparation of CNFs from MCC by using ACCsystem. The diameter of CNFs was ca. $15 \mathrm{~nm}$ and the length was ca. $700 \mathrm{~nm}$. It is worth noting that in sequence to avoid clogging, the size of processed cellulosic material should be less than the nozzle diameter (ca. $150 \mu \mathrm{m})$.

\section{Enzyme Hydrolysis}

The hydrolysis of cellulose can be catalysed by some enzymes and the fibrillation can also be improved. The enzyme pre-treatment has a mild state and a high selectivity and can make fibers produce holes, peeling, and fine fibrosis, which is conducive to the nano fibrillation of cellulose in following mechanical processes and reduces the probability of blocking the homogeneous valve by cellulose slurry. The enzyme system could be multicomponent enzyme blend or the nanocomponent. According to the reports, the monocomponent endoglucanase seems to give a better pretreatmenteffect.

\section{TEMPO Oxidation}

As we all know that the negatively charged groups (such as carboxyl or carboxymethyl) are introduced into cellulosic fibers and then the delamination of the nanofibrils can be initiate, since there is electrostatic repulsion in the middle of cellulose nanofibrils with negative charge. The procedure of 2,2,6,6-tetramethylpiperidine-N-oxyl (TEMPO) radical oxidizing the primary alcohol groups of monosaccharides to carboxylic groups was reported by Davis and Flitsch in 1993 which has become one of the most sizeable research topics in the area of oxidation of cellulose. The classical oxidation system for cellulose is TEMPO/ $\mathrm{NaBr} / \mathrm{NaClO}$, which has been extensively used for the pre-treatment of raw cellulose materials ahead mechanicaldisintegration. 


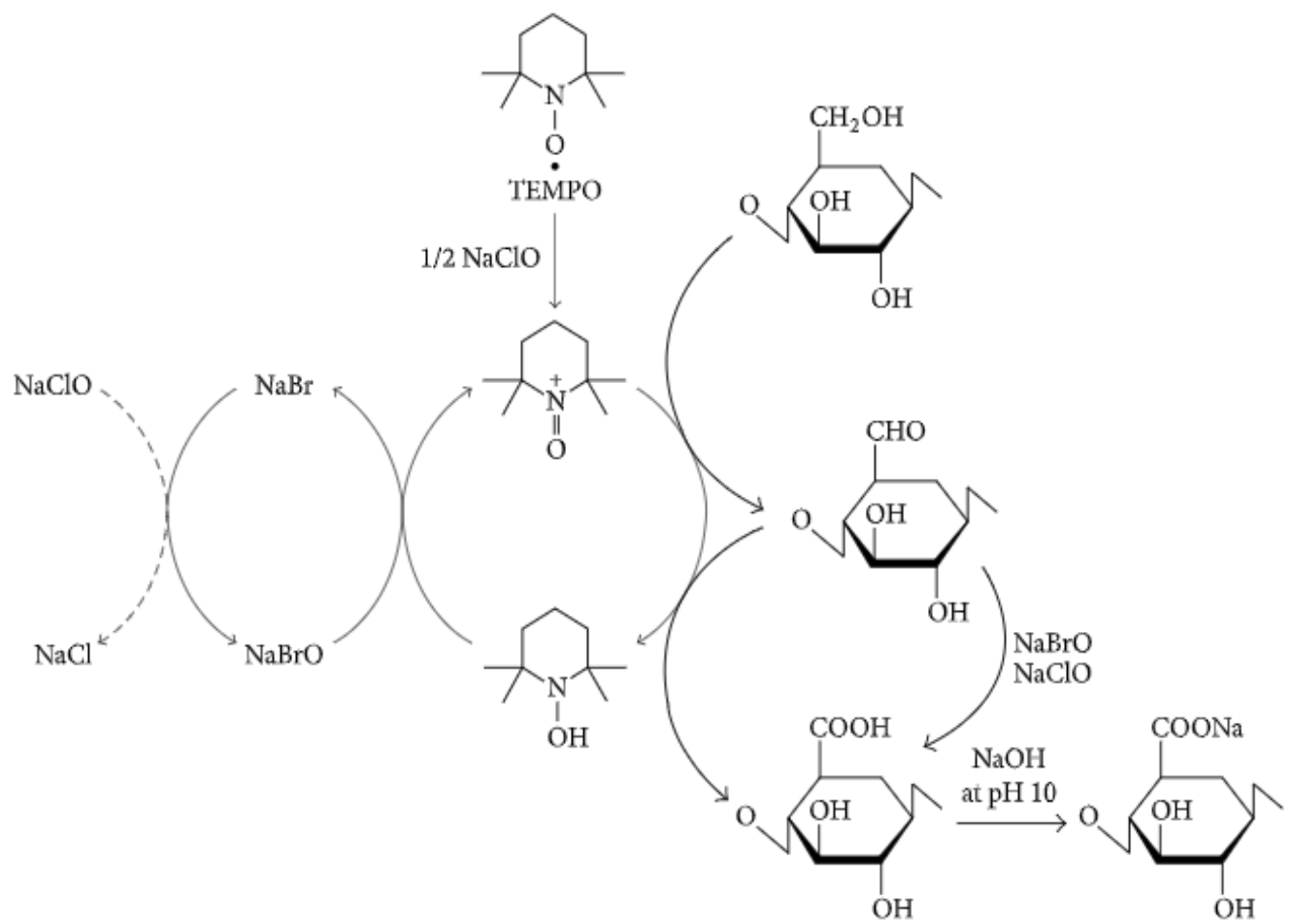

\section{Fig regioselective oxidation of c6 primary hydroxyls of cellulose to c6 carboxylate groups by TEMPO system in water at $\mathrm{pH}$}

Nitrosonium ions $(+\mathrm{N}=\mathrm{O})$ are generated in situ during the reaction of TEMPO radicals with the oxidants and they are used to oxidize the cellulose fibers. Consequently, the primary alcohol groups are first oxidized to aldehydes and further converted to carboxyl groups. At the same time, the depolymerization phenomenon of cellulose appears. There are two phenomena which may be caused by cellulose depolymerization: (i) $\beta$-elimination could occur owing to $\mathrm{C} 6$ aldehyde groups presented in an alkaline environment and (ii) the cleavage of a hydro glucose unit took place unpaid to the existing of hydroxyl radicals. TEMPO/ $\mathrm{NaClO} / \mathrm{NaClO}_{2}$ structure was also applied which overcame the depolymerization. The reaction was carried out in the neutral or weakly acidic environment and at $60^{\circ} \mathrm{C}$ for $72 \mathrm{~h}$. The results demonstrated that most of original DP remained unchanged. TEMPO oxidation pretreatment remarkably reduced the energy consumption for the further mechanical disintegration of cellulose. Nelson et al. evaluated that the mechanical energy consumption after TEMPO oxidation was around
$570 \mathrm{KWh} / \mathrm{t}$, which was far lower than that of $70000 \mathrm{KWh} / \mathrm{t}$ without any pre-treatment.

\section{Periodate-Chlorite Oxidation}

Periodate-chlorite is an effective oxidation structure for transferring secondary alcohols of cellulose to carboxyl groups. Liimatainen et al. used this procedure to oxidize cellulose to advance further mechanical decomposition of cellulose. During the reaction, secondary alcohols of cellulose were firstly converted to aldehydes by sodium periodate, which were further oxidized to carboxyl groups by sodium chlorite. The CNFs with the diameter of $3-5 \mathrm{~nm}$ were obtained through sequential highpressure homogenization for up to 4 passes. In this method, the glucopyranose ring was opened to prepare 2,3-dicarboxylic acid cellulose. Moreover, the strength property of CNFs was not decreased by ring opening reaction. 


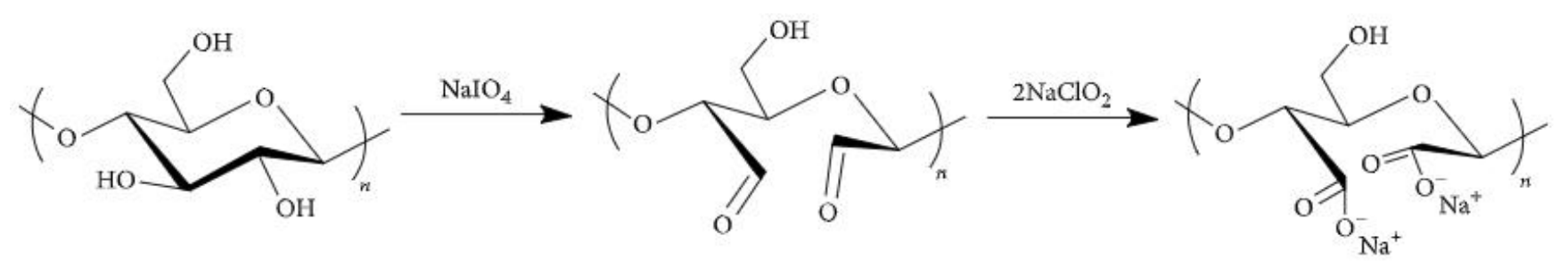

(a)

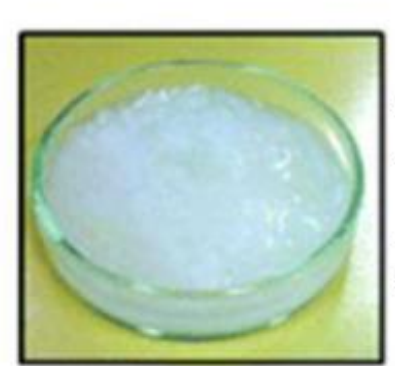

Cellulose pulp fibers

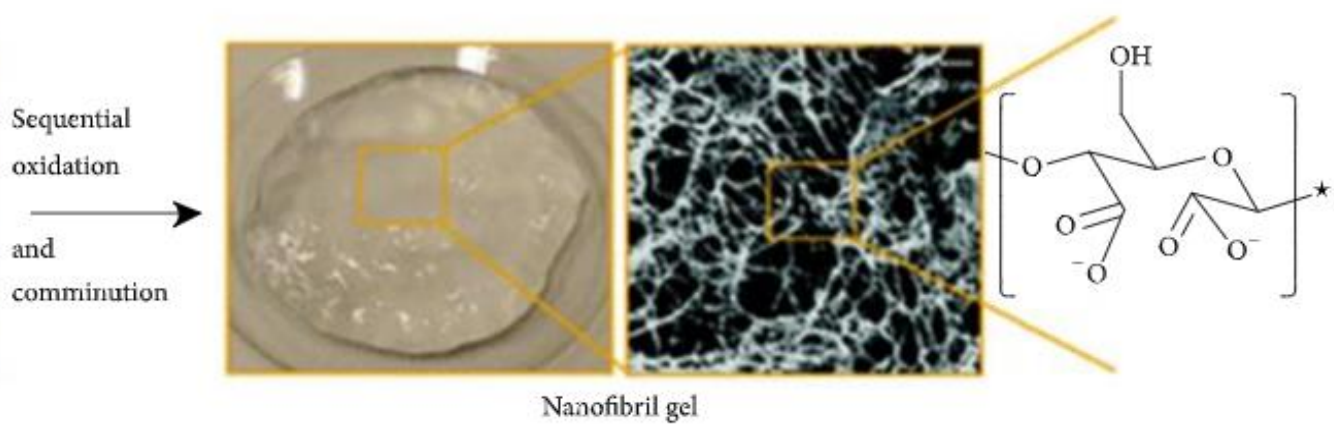

(b)

schematic diagram of cellulose carboxylation via periodate-chloride;

a. chemical formula for cellulose carboxylation

b. preparation of CNFs by periodate-chlorite oxidative system.

\section{Oxidative Sulfonation}

Oxidative sulfonation of cellulose is another procedure for introducing negative charge groups onto the surface cellulose and can be used to enhance the fibrillation process. Liimatainen et al. treated bleached kraft hardwood pulp with periodate and bisulfite, and CNFs with typical diameter of 10 $60 \mathrm{~nm}$ were obtained by the following high-pressure homogenization for 5 times. In this method, the used periodate could be efficiently recycled, so it is a potential green procedure for the pre-treatment of cellulose.

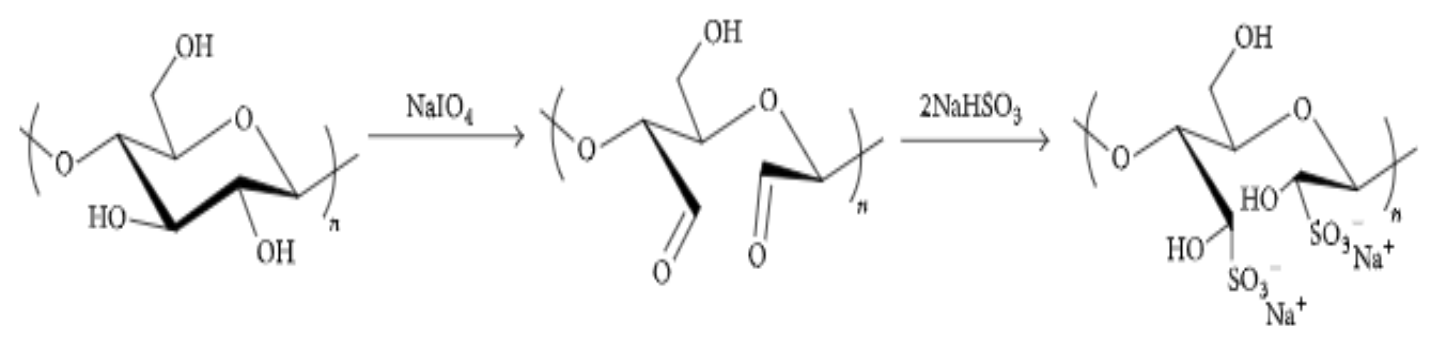

Schematic diagram of cellulose sulfonation via periodate treatment

\section{Carboxymethylation}

Carboxymethylation is another procedure for the pre-treatment of cellulose. The hydroxyl groups on cellulose could react with 1chloroacetic acid under strong alkaline conditions to give the carboxymethylation products. Wågberg et al. reported the manufacture of CNFs from carboxymethylated cellulose by high pressure homogenization. The resultant CNFs had a cylindrical cross section with the width of 5-15 nm and the length of ca. $1 \mu \mathrm{m}$. Chen et al. reported the preparation of CNFs by high pressure homogenization of carboxymethylated cellulose raw fiber. In this work, the carboxymethylation pre-treatment included two steps: (1) basification of raw oven-dried cellulose fibers by using anhydrous $\mathrm{NaOH} /$ dimethyl sulfoxide; (2) further sodium acetoxylation of cellulose raw fibers by using sodium chloroacetate. Then the resultant MCC was extracted by deionized water which was beneficial to the collapse of the cell wall of cellulose fibers. Finally, the pre-treated cellulose fiber suspension passed through homogenizer to give the CNFs. The resultant CNFs were used for manufacture of nano paper which exhibited $90.5 \%$ optical transparency. Carboxymethylation pre-treatment was also used by other researchers for preparing CNFs. Overall, the carboxymethylation method is also a potential green pre-treatment technology for the preparation of CNFs. 

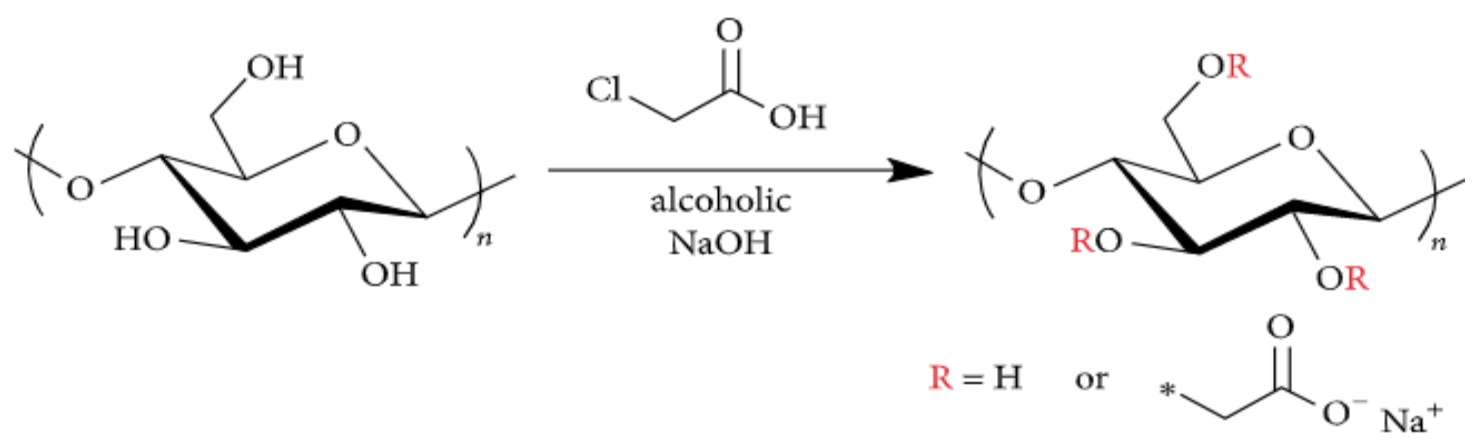

(a)

schematic diagrams of a. chemical formula for carboxymethylation of cellulose by using chloroacetic acid and b. carboxymethylation pre-treatment of cellulose for the preparation of CNFs and the application of resultant CNFs as nano paper and flexible electrode.

\section{Cationization}

The cationization of cellulose could be used for encourage the nano fibrillation of cellulose. In the process, the cations were initiate on the surface of cellulose by the quaternization of cellulose. The fibrillation of cellulose was promoted by the electrostatic repulsion between the quaternary ammonium cations. This method has been used for preparation of CNFs combination with following mechanical disintegration: (2,3epoxypropyl) trimethylammonium chloride, (2-chloroethyl) trimethylammonium chloride, and (2-hydrazinyl-2-oxoethyl)trimethylazanium chloride were commonly used as cationization reagents. The process was carried out under alkaline environment, for example, $\mathrm{NaOH} / \mathrm{H}_{2} \mathrm{O} /-\mathrm{PrOH}, \mathrm{NaOH} / \mathrm{DMSO}$. Recent studies showed that, owing to significant antibacterial properties of cationic CNF film, and without quaternary ammonium leaking to the environment, they could be applied into wound healing, food packaging, tissue, and so on.

\section{Deep Eutectic Solvent Pretreatments}

Deep eutectic solvent (DES), which is composed of two or more compounds, has lower melt point than any component of its own. Due to its low cost, low toxicity, and recyclability, DES has been widely used in various fields. Sirviö and workers proposed a bio-based DES consisting of urea and choline chloridewhich could be used to the pre-treatment of cellulose pulp. Li and co-workers used the urea-based DES as the pretreatment for the preparation of CNFs. In this work, DES was composed of urea and ammonium thiocyanate or guanidine hydrochloride and was used to tend wood-derived cellulose fibers. The results showed that the cellulose fibers were well loosened and swelled by both DES systems. Then CNFs with the width of $13.0-19.3 \mathrm{~nm}$ were smoothly obtained through further mechanical nano fibrillation without clogging. A method for the preparation of anionic CNFs using DES as reaction medium was proposed by Sirvio and Visanko. As is shown in Figure 16, the DES consisted of triethyl methylammonium chloride (TEMACl) and imidazole was liquid at room temperature. The ground wood pulp with a $27.4 \mathrm{wt} \%$ lignin was carboxylated by succinic anhydride during the DES pretreatment process under mild reaction conditions $\left(2 \mathrm{~h}\right.$ at $\left.70^{\circ} \mathrm{C}\right)$. Then the anionic CNFs could be prevail through the followed micro fluidization of carboxylated ground wood pulp. A microwave-assisted DES pre- treatment method for fast CNCs production was proposed by Liu and coworkers. It took only a little time (not more than $3 \mathrm{~min}$ ) for the pretreatment of cotton, and then a high-intensity ultrasonication process was adopted. The resultant CNCs with the diameter of 3-25 nm and the length of $100-350 \mathrm{~nm}$ were obtained at a yield of $74.2 \%$. Overall, DES pretreatment is efficient and environment-friendly and is a promising technology for the industrial production of NCs.

\section{Chemical Hydrolysis:}

The NFCs produced by mechanical methods consist of alternating crystalline and amorphous regions within the single cellulose domains. In order to dissolve the amorphous domain and permit longitudinal cutting of microfibrils, strong but controlled acid hydrolysis treatment is performed. The obtained nanocellulose, as an aqueous suspension reveals crystallinity greater than $90 \%$, are termed as CNCs. In the acid hydrolysis process, the hydronium ion enters the amorphous regions of cellulose chains and promotes the hydrolytic cleavage of the glycosidic bonds. A mechanical treatment for nanocellulose dispersion, such as sonication, is required to prevent agglomeration. Various strong acids have been studied successfully to degrade cellulose fiber but the most common are hydrochloric and sulfuric acids. However, for the preparation of crystalline cellulosic nanoparticles, phosphoric acid, as well as hydrobromic and nitric acids, were recommended ${ }^{(20)}$. The benefit of using sulfuric acid as hydrolyzing agent is it initiates the esterification process on the cellulose surface and promotes the grafting of anionic sulfate ester groups. Furthermore, the presence of anion groups induces the formation of a negative electrostatic layer on the surface of the nanocrystals and helps their dispersion in water. However, it reduces the agglomeration and reduces the thermostability of the nanoparticles. The reduced thermal stability of H2SO4-prepared CNCs can be improved by 270 CelluloseReinforced Nanofiber Composites neutralizing by sodium hydroxide. However, these nanoparticles possess high aspect-ratio, rod-like nanocrystals, their geometrical dimensions depend on the source of cellulose and hydrolysis methods. The length of the CNCs varies widely in the range of a few hundred nanometers due to the diffusion control nature of the acid hydrolysis, while the width is in the range of nanometers (21). Acid hydrolysis is the easiest and oldest method of CNC preparation. Recently, some other methods have been studied that degrade the 
amorphous domain from cellulosic fibers, such as enzymatic hydrolysis treatment, TEMPO-mediated oxidation, and treatment with ILs.

\section{Characterization:}

\section{Scanning Electron Microscopy:}

The surface morphology of the samples was carried out using Phenom World ProX desktop scanning electron microscope with fully integrated and specifically designed EDS detector made in Eindhoven Netherlands (22).

\section{FT-IR results of Cellulose, Methylcellulose and Cellulose acetate nanoparticles:}

The FT-IR spectra of samples were recorded FT-IR-8400S Fourier Transform Infrared Spectrophotometer in the spectra range of 4000-400 $\mathrm{cm}-1$. Samples were run as (Kbr) pellets.

\section{X-Ray Diffraction (XRD) Analysis of samples:}

$\mathrm{X}$-ray diffractometry in reflection mode was carried out using a diffractometer (DLMAX-2550, Japan), with monochromatic $\mathrm{Cu} \mathrm{K \alpha}$ radiation $(\lambda=0.154 \mathrm{~nm})$, with a divergence and scatter at $1.00 \mathrm{o}$, and a receiving slit at $0.30 \mathrm{~mm}$, generated at $40 \mathrm{kV}$ and $30 \mathrm{~mA}$, at room temperature. The samples were scanned within $2.00-70.00^{\circ} 2 \theta$ in continuous scan mode with a step of $0.02^{\circ}$ and a rate of $0.10 \mathrm{sec}$. The crystallite index of cellulose was calculated using the Kim's empirical method.

$\mathrm{CI}=(\mathrm{I} 002-\mathrm{Iam}) / \mathrm{I} 002 \times 100$ Where $\mathrm{CI}$ is the crystallinity index, I002 is the maximum intensity and represents crystalline material, while Iam represents maximum intensity of the amorphous material.

\section{Thermogravimetric Analysis (TGA):}

Thermal behavior of the prepared samples was examined by Thermogravimetric Analyzer model Schimadzu TGA-50H (Kyoto, Japan) from $28{ }^{\circ} \mathrm{C}$ to $900{ }^{\circ} \mathrm{C}$. A heating rate of the analysis was $10{ }^{\circ} \mathrm{C} /$ min under nitrogen atmosphere and at a flow rate of $20 \mathrm{~mL} / \mathrm{min}$.

\section{BET Analysis:}

The surface area of the prepared samples was examined by BET analysis using Quanta chrome NovaWin-Data Acquisition and Reduction for NOVA instruments version 11.03.

\section{Applications of nanocellulose:}

\section{Nanocellulose in Microparticulate Drug Delivery:}

The importance of encapsulating drugs, food actives, flavors, or even cell for improved performance and preservation has been well appreciated across different scientific fields. A broad range of natural and synthetic polymeric materials are available for encapsulation, the choice of which mainly rested upon the desired performance of the end products. Nanocellulose is an emerging natural polymer that has received considerable interest in recent years as the encapsulating polymer for drug delivery ${ }^{(23)}$. It has also been widely investigated to enhance the mechanical properties and influence drug delivery behavior of microcapsules prepared with other natural polymers. A study was conducted to estimate the influence of three polysaccharide nanocrystals (PNs) such as CNCs, starch nanocrystals, and chitin whiskers on the mechanical and drug release properties of sodium alginate microspheres. All the three PNs resulted in ameliorated mechanical properties and $\mathrm{pH}$ sensitivity of the microspheres. All the PNs were found to restrict the motion of the sodium alginate polymer chains and inhibit diffusion of the drug, resulting in the slow dissolution of theophylline from the microspheres, and diffusion transport was found to be the drug release mechanism from the systems.

Nanocellulose in Tablet Formulations:
Cellulose and its derivatives in different forms have been indispensable components in the preparation of tablets for a long time. Cellulose derivatives such as MCC, hydroxypropyl methylcellulose, ethyl cellulose, carboxymethylcellulose, and others are extensively used in conventional as well as controlled-release tablet formulations. With the practical edge supplied by nanocellulose in numerous functional properties being realized and appreciated, a few investigations have explored its potential as functional excipients in tablet formulations. The potential of spraydried cellulose nanofibers as novel tablet excipients was evaluated and compared against two commercial MCC, Avicel PH-101 and Avicel PH102 , which are the two most commonly used direct compression excipients (24). Cellulose nanofibers were found to possess better compressibility and were amendable to both wet granulation and direct compression methods of tablet preparations. Cellulose nanofibers formulated through direct compression method showed faster disintegration and drug release showing its potential as direct compression excipients. Freeze-dried $\mathrm{CNC}$ prepared from water sugarcane bagasse was also shown to increase the dissolution of diltiazem hydrochloride tablets prepared with the nanocellulose.

\section{Aerogel Systems:}

Aerogels are insubstantial materials with excellent surface area and open porosity, suitable for high loading of active compounds. They are nano porous systems procured from the wet gels or hydrogels through an acceptable drying technology that keeps the porous texture of the wet material intact. Due to their web like structure, high porosity, and high surface reactivity, aerogels prepared from nanocelluloses possess a high mechanical flexibility and ductility with ability for water uptake, which makes them an excellent applicant for the removal of dye pollutants, thermal insulation materials, and drug delivery system ${ }^{(25)}$. As a result, different types of nanocelluloses, due to their outstanding and acceptable properties, have become the subject of keen interest in the preparation of aerogels for drug delivery.

\section{Hydrogels:}

Hydrogels are produced by cross-linking of polymer chains through the interactivity that may be of ionic, physical, or covalent, having the capacity to absorb water ${ }^{(26)}$.Hydrogels expand in water but do not dissolve in it. Due to their ability to display sol-gel transitions that can be induced by a slight changes in the environmental conditions such as temperature, $\mathrm{pH}$, ionic strength, phase separation, wavelength of light, crystallinity, and others, bright polymeric hydrogels are extensively used in biomedical fields such as in the growth of controlled-release drug delivery systems, tissue engineering, and regenerative medicine ${ }^{(27)}$. Several smart hydrogels such as injectable hydrogels, shape-memory bacterial nanocellulose hydrogels, supramolecular hydrogels, doublemembrane hydrogels, temperature-sensitive hydrogels, and many others with possibilities for drug delivery have been developed, which were based on nanocellulose.

\section{Nanocellulose in Transdermal Drug Delivery:}

Delivery of drugs through the skin offers several leads over other routes as well as elimination of first-pass metabolism, minimization of pain, prolonged release of the drug, and the potential to terminate drug absorption by removing the patch from the skin ${ }^{(28)}$. Nanocellulose, mainly bacterial cellulosic sources, has entice a great deal of interest in the development of controlled transdermal drug delivery and woundalleviate preparations.

\section{Conclusion:}

Nanocellulose prepared from wood cellulose has unique and promising properties, such as high crystallinity, aspect ratio, Young's moduli, and tensile strengths, which originate from the properties of natural wood 
cellulose microfibrils. A change in processing technique changes the properties of the resulting nanocellulose, which is reflected in the final product. Besides the conventional mechanical methods traditionally used to prepare CNFs, such as grinding or homogenization, other promising methods are discussed, which can be instrumental to further research and industrialization of these materials. This review explains the preparation methods of CNCs and CNFs. For the preparation of CNCs, promising abilities were discussed besides the conventional mineral acid hydrolysis, such as organic acid hydrolysis, subcritical hydrolysis, AVAP method, and ionic liquid hydrolysis. Most of them have great feasibility for further industrialization.Different methods of nanocellulose like pretreatment method, mechanical process and chemical hydrolysis used for the synthesis of nanocellulose. Characterization of cellulose includes scanning electron microscopy, x-ray diffraction (xrd) analysis of samples, thermogravimetric analysis (TGA).

\section{References}

1. Habibi, Y, Lucian A. L,Orlando J. R (2010). Chem. Rev., 110.

2. Samir, M. A. S. Azizi, Alloin, F (2005), Dufresne, A. Biomacromolecules.

3. Chakraborty, A (2004). Ph.D. Thesis, Department of Chemical Engineering and Applied Chemistry, University of Toronto,

4. Preston, R. D. Discussion of the Faraday Society 1951, 11, 165-170. 11. Henriksson, M.; Henriksson, G.; Berglund, L. A.

5. Herrick FW, Casebier RL, Hamilton JK, Sandberg KR (1983). Microfibrillated cellulose: mor-phology and accessibility. J Appl Polym Sci Appl Polym Symp.

6. Keerati-U-Rai M, Corredig M (2009). Effect of dynamic high-pressure homogenization on the ggregation state of soy protein. J Agric Food Chem.

7. Habibi Y, Mahrouz M, Vignon MR (2009). Microfibrillated cellulose from the peel of prickly pear fruits. Food Chem.

8. Lee S-Y, Chun S-J, Kang I-A, Park J-Y (2009). Preparation of cellulose nanofibrils by high-

pressure homogenizer and cellulose-based composite films. $J$ Ind Eng Chem.

9. Iwamoto S, Kai W, Isogai A, Iwata T (2009). Elastic modulus of single cellulose microfibrils from tunicate measured by atomic force microscopy. Biomacromolecules.

10. Cheng Q, Wang S, Rials TG (2019). Poly (vinyl alcohol) nanocomposites reinforced with cel-lulose fibrils isolated by high intensity ultrasonication. Composites, Part A.

11. Filpponen I, Argyropoulos DS. Regular linking of cellulose nanocrystals via click

Chemistry : synthesis and formation of cellulose nanoplatelet gels. Biomacromolecules

12. Zhang L., Liu Z., Cui G., Chen L (2015). Biomass-derived materials for electrochemical energy storages. Progress in Polymer Science.

13. Ching Y. C, Ali M. E., Abdullah L. C., Choo K. W., Kuan Y. C., Julaihi S. J., Chuah C. H(2016). Liou N-S.: Rheological properties of cellulose nanocrystal-embedded polymer composites: A review. Cellulose

14. Abraham E., Kam D., Nevo Y., Slattegard R., Rivkin A., Lapidot S., Shoseyov O. (2016). Highly modified cellulose nanocrystals and formation of epoxy-nanocrystalline cellulose (CNC) nanocomposites. ACS Applied Materials and Interfaces

15. Abraham E., Kam D., Nevo Y., Slattegard R., Rivkin A., Lapidot S., Shoseyov O. (2016). Highly modified cellulose nanocrystals and formation of epoxy-nanocrystalline cellulose (CNC) nanocomposites. ACS Applied Materials and Interfaces.

16. Yang J, Han C (2016). Mechanically viscoelastic properties of cellulose nanocrystals skeleton reinforced hierarchical composite hydrogels. ACS Applied Materials and Interfaces.

17. Klemm D, Schumann D, Kramer F, Hessler N, Hornung M, Schmauder H-P, Marsch S. (2006). Ioelovich M. (2008). Cellulose as a nanostructured polymer: a short review. Bioresources.

18. Herrick F.W ,Casebier R.L, Hamilton J.K., Sandberg K.R. (1983). Microfibrillated cellulose:

19. morphology and accessibility. J. Appl. Polym. Sci, Appl. Polym. Symp.

20. Turbak A.F., Snyder F.W., Sandberg K.R. (1983). Microfibrillated cellulose, a new cellulose product: properties, uses, and commercial potential. J. Appl. Polym. Sci., Appl Polym Sym.

21. Siro I., Plackett D. (2010). Microfibrillated cellulose and new nanocomposite materials: a review.

22. D. Trache, M. H. Hussin, M. K. M. Haafiz, and V. K. Thakur (2017). "Recent progress in cellulose nanocrystals: Sources and production," Nanoscale, vol. 9, no. 5, pp. 1763-1786.

23. S. Boufi (2017) "6 - Agricultural crop residue as a source for the production of cellulose nanofibrils," in celluloseReinforced Nanofibre Composites, pp. 129-152, Woodhead Publishing.

24. H. Lee, J. Sundaram, and S. Mani (2017)"Production of cellulose nanofibrils and their application to food: a review," in Nanotechnology: Food and Environmental Paradigm, R. Prasad, V. Kumar, and M. Kumar, Eds., pp. 1-33, Springer, Singapore,

25. B. L. Peng, N. Dhar, H. L. Liu, and K. C. Tam (2011). "Chemistry and applications of nanocrystalline cellulose and its derivatives: a nanotechnology perspective," The Canadian Journal of Chemical Engineering, vol. 89, no. 5, pp. 1191-1206.

26. Y. Habibi, L. A. Lucia, and O. J. Rojas (2010). "Cellulose nanocrystals: chemistry, self-assembly, and applications," Chemical Reviews, vol. 110, no. 6, pp. 3479 3500 .

27. J. F. Revol, L. Godbout, X.-M. Dong, D. G. Gray, H. Chanzy, and G Maret (1994) "Chiral nematic suspensions of cellulose crystallites; phase separation and magnetic field orientation," Liquid Crystals, vol. 16, no. 1, pp. 127-134.

28. X. M. Dong and D. G Gray Gray (1997)., "Induced circular dichroism of isotropic and magnetically-oriented chiral nematic suspensions of cellulose crystallites," Langmuir,.

29. R. J. Moon, A. Martini, J. Nairn, J. Simonsen, and J. Youngblood, "Cellulose nanomaterials review: structure, properties and nanocomposites," Chemical SocietyReviews, vol. 40, no. 7, pp.

30. Mei-Chun Li, Qinglin Wu, Jingquan Han, Changtong Mei, Tingzhou Lei, Sun-young Lee, Jaegyoung Gwon. Overcoming Salt Contamination of Bentonite WaterBased Drilling Fluids with Blended Dual-Functionalized Cellulose Nanocrystals.

31. Chun-Wei Lai, Sheng-Sheng Yu. 3D Printable Strain Sensors from Deep Eutectic Solvents and Cellulose Nanocrystals.

32. Aline Merlini, Carlos Claumann, André Wust Zibetti, André Coirolo, Tailin Rieg, Ricardo A. F. Machado (2020). Kinetic Study of the Thermal Decomposition of Cellulose Nanocrystals with Different Crystal Structures and 
Morphologies. Industrial \& \& Engineering ChemistryResearch, Article ASAP.

33. Ning Tang, Yuyao Li, Jianlong Ge, Yang Si, Jianyong Yu, Xia Yin, Bin Ding. Ultrathin Cellulose Voronoi-Nanonet Membranes Enable High-Flux and Energy-Saving Water Purification.

34. Mohit Garg, Mathieu Linares, Igor Zozoulenko. Theoretical Rationalization of Self-Assembly of Cellulose Nanocrystals: Effect of Surface Modifications and Counterions. .

35. Liu, Q. et al (2009). Chromosomal aberrations and DNA damage in human populations exposed to the processing of electronics waste. Environ. Sci. Pollut. Res. 16, 329-338.

36. Musson, S. E. et al (2006). RCRA Toxicity characterization of discarded electronic devices. Environ. Sci. Technol. 40, 2721-2726.
37. Colinge, J.-P (2004). Silicon-on-Insulator Technology: Materials to VLSI 3rd edn. Ch. 1, Springer.

38. Webb, D. R., Wilson, S. E. \& Carter, D. E ((1986). Comparative pulmonary toxicity of gallium arsenide, gallium (III) oxide, or arsenic (III) oxide intratracheally instilled into rats. Toxicol. Appl. Pharmacol. 82, 405-416.

39. Webb, D. R., Sipes, I. G. \& Carter, D. E ((1984).In vitro solubility and in vivo toxicity of gallium arsenide. Toxicol. Appl. Pharmacol. 76, 96-104

40. Chung, H.-J. et al ((2011). Fabrication of releasable singlecrystal silicon-metal oxide field-effect devices and their deterministic assembly on foreign substrates. Adv. Funct. Mater. 21, 3029-3036.
This work is licensed under Creative Commons Attribution 4.0 License
To Submit Your Article Click Here: $\quad$ Submit Manuscript

DOI: $10.31579 / 2693-7247 / 039$
Ready to submit your research? Choose Auctores and benefit from:

$>$ fast, convenient online submission

$>$ rigorous peer review by experienced research in your field

$>$ rapid publication on acceptance

$>$ authors retain copyrights

$>$ unique DOI for all articles

$>$ immediate, unrestricted online access

At Auctores, research is always in progress.

Learn more https://auctoresonline.org/journals/pharmaceutics-andpharmacology-research 